\title{
Speciation of rare earth elements in soil and accumulation by wheat with rare earth fertilizer application
}

\author{
Shuzhen Zhang, Xiao-quan Shan* \\ Research Center for Eco-Environmental Sciences, Chinese Academy of Sciences, PO Box 2871, Beijing 100085, People's Republic of China
}

Received 26 August 1999; accepted 8 May 2000

"Capsule": Rare earth elements increased wheat yields and accumulated in plants in relation to concentrations in fertilizers.

\begin{abstract}
A greenhouse study was conducted to investigate the accumulation of rare earth elements (REEs), La, Ce, Pr and Nd, in winter wheat (Triticum aestivum L.), and the speciation of these elements in soil following the application of REE-based fertilizers. Improved crop yield was confirmed by the experiment. The accumulation behavior of $\mathrm{La}, \mathrm{Ce}, \mathrm{Pr}$ and $\mathrm{Nd}$ in wheat varied depending on the concentration of REE fertilizer application, i.e. increased with increasing REE concentration at low fertilization application, constant over the medium REE range, and decreased with increasing REE concentration at high fertilizer application. Significant negative correlation was obtained between REE contents in roots and soil pH ( $r=-0.5787$ to -0.8442 for La). REEs in both the fertilized and unfertilized soils were fractionated by a three-stage sequential extraction procedure into three chemically distinct fractions: water soluble, exchangeable and carbonate bound (B1), Fe-Mn oxide bound (B2), and organic and sulfide bound (B3). REEs in fertilized soils were found mainly in the B2 and B3 fractions, with only a small amount in the B1 fraction. REEs in B1 and $\mathrm{B} 2$ fractions were negatively correlated with soil $\mathrm{pH}(r=-0.6892$ to -0.8927 and -0.7462 to -0.9482$)$. Significant correlation was obtained between REEs in B1 fraction and REE contents in root. The correlation coefficients ranged from 0.6159 to 0.7410 when fertilizer application was lower than $20.0 \mathrm{mg} / \mathrm{kg}$ soil. No acceptable relationship was observed between REE contents in shoot and any of the extractable fractions in soils. (C) 2001 Elsevier Science Ltd. All rights reserved.
\end{abstract}

Keywords: Rare earth elements; Accumulation; Bioavailability; Fertilizer; Speciation

\section{Introduction}

In recent years, the usage of rare earth elements (REEs) has been increasing rapidly, in particular in industrial and agricultural applications. China has the largest REE reserves in the world $(80 \%)$ and is a major supplier for the world market. The use of REE-based fertilizers have been widely practiced in China since 1990 (Wu and Guo, 1995; Yu and Chen, 1995). Enhanced yield and improved quality of the crops because of REE applications have been reported (Guo, 1985; Ning, 1985). However, as a result of their usage, more and more REEs are getting into the environment. Continuous exposure to low concentrations of REEs

\footnotetext{
* Corresponding author. Tel.: + 86-10-62923560; fax: + 86-1062923563.

E-mail address: xiaoquan@mail.rcees.ac.cn (X.-q. Shan).
}

could cause adverse health effects because of their bioaccumulation along the food chain. Although there is so far no reported incidence of intoxication due to the intake of REEs through the food chain, several deleterious effects due to occupational and environmental exposure to REEs have been reported (Sabbioni et al., 1982; Ding and Ma, 1984; Sax, 1984).

It has been forecasted that the agricultural usage of REEs and the resulting environmental contamination by REEs will continue to grow in the next few decades (Volokh et al., 1990). The REEs from anthropogenic sources usually get into the environment in biologically available forms, which is of particular concern because they may dislocate the balance of the biogeochemical cycle of these species. Thus, well-designed studies are needed to determine the extent of REE accumulation in different types of soils, and to study the responses and uptake of REEs by crops because of fertilizer application. There is also a pressing need to speciate the REEs 
in the soils in order to gain understanding on the bioavailability of different compound types of REE species.

Many reports have been published in which the distribution and abundance of REEs are studied from a geochemical or mineralogical viewpoints (Scott, 1990; Wronkiewicz and Condie, 1990; Liu et al., 1993). On the other hand, literature information on the environmental effects, bioaccumulation and bioavailability of REEs has received scant attention until very recent years. Starting from the late 1990s, increasing effort has been directed to the environmental effects of REEs, and some of the recent reports include the study of REE accumulation in plant (Ichihashi et al., 1992), soil (Wyttenbach et al., 1998), sediment (Zhu et al., 1997) and biological samples (Tu et al., 1994).

It is against the above background that this study was initiated. Our aims in the present work are to: (1) evaluate the accumulation of REEs in wheat after fertilizer application in different types of soils; (2) speciate the chemical types of REEs in soils after REE fertilizer application; and (3) investigate the relationship between plant uptake and chemical speciation of REEs.

\section{Experimental}

\subsection{Soil and REE samples}

Soil samples $(0-20 \mathrm{~cm})$ were collected from different rural regions in China. They were all cultivated soils with different physico-chemical properties. The soil samples were air-dried and ground to pass through a 2-mm sieve, homogenized and analyzed. Soil $\mathrm{pH}$ was measured in aqueous slurry of 1:1 soil and water mixture. Organic matter in soil was determined by the WalkleyBlack method (Nelson and Sommers, 1982). Cation exchange capacities (CECs) of soils were determined by the method described by Rhoades (1982). Selected properties of the soil samples are presented in Table 1 .

The REE fertilizer used in this study, trade-named Changle, is commercially available. The main components of Changle REEs are La (23.95\%), Ce (41.38\%), $\operatorname{Pr}(4.32 \%)$ and $\mathrm{Nd}(13.58 \%)$, all in their nitrate forms. Only these four REE elements are studied in this work.

\subsection{Potting experiment}

For potting experiment, $1 \mathrm{~kg}$ soil was placed in plastic pots. Known amounts of Changle fertilizer were added to the soil and the two mixed thoroughly. The levels of Changle fertilizer applied were $0,0.4,2.0,8.0,20,40$ and $80 \mathrm{mg}$, respectively, per kilogram of soil.

Winter wheat (Triticum aestivum L.) was sown at 20 seeds per pot. It was subsequently thinned to 10 plants per pot after germination. Soil water content was roughly maintained at close to $15 \%$ by adding deionized water daily. The plants, both the shoot and root parts, were harvested 8 weeks after germination. The shoot of each plant was harvested by clipping it near the soil surface, washing with dilute detergent solution, followed by several rinses with de-ionized water. The roots were separated from the soil and washed with deionized water. The plant materials were then dried at $70^{\circ} \mathrm{C}$ for $48 \mathrm{~h}$, and the dry weights were recorded. The dried plant tissue was finely ground before elemental analysis.

The soils after harvest were collected from each pot, air-dried, mixed, and then sieved to pass through a 2-mm mesh sieve. The $\mathrm{pH}$ of the soil was measured for each pot. Mean soil $\mathrm{pH}$ changed $\pm 0.3 \mathrm{pH}$ unit compared with those before planting.

\subsection{Speciation of REEs}

Speciation of REEs in soils was conducted by a sequential, three-stage fractionation procedure proposed by the Community Bureau of Reference (BCR) (Quevauviller et al., 1993), which is now called the Standard Measurements and Testing Programme of the European Community (SMT). Details of the extraction processes are given in Table 2. The extractions were performed for $0.500 \mathrm{~g}$ of dried soil samples placed individually in $50-\mathrm{ml}$ polypropylene centrifuge tubes. Duplicate runs were made for each sample and the averaged results were used for yield calculations. Following each extraction, the mixture was centrifuged to separate the supernatant and the residues. The residues were washed with de-ionized water, and the washings were combined into the supernatant fraction. The

Table 1

Selected properties of studied soils

\begin{tabular}{llllll}
\hline Sample & Geographical origin & Order & Cation exchange capacity $(\mathrm{cmol} / \mathrm{kg})$ & $\mathrm{pH}$ & Organic matter $(\%)$ \\
\hline 1 & Jiangxi & Ultisol & 14.24 & 4.63 & 1.53 \\
2 & Hunan & Alfisol & 26.56 & 5.48 & 4.14 \\
3 & Hefei & Entisol & 24.95 & 6.71 & 2.09 \\
4 & Beijing & Mollisol & 16.82 & 7.09 & 1.90 \\
5 & Heilongjiang & Mollisol & 45.20 & 7.16 & 5.28 \\
6 & Shannxi & Mollisol & 7.55 & 7.48 & 1.68 \\
7 & Zhongxin & mollisol & 15.71 & 8.28 & 1.35 \\
\hline
\end{tabular}


Table 2

Sequential extraction scheme for rare earth elements (REEs) fractionation in soil

\begin{tabular}{|c|c|c|}
\hline Step $^{\mathrm{a}}$ & Phases & Procedure \\
\hline 1 & B1: water soluble, exchangeable and carbonate bound & $0.1 \mathrm{M} \mathrm{CH}_{3} \mathrm{COOH}, 20 \mathrm{ml}$, room temperature, shake for $16 \mathrm{~h}$ \\
\hline 2 & B2: Fe-Mn oxide bound & $0.1 \mathrm{M} \mathrm{NH}_{2} \mathrm{OH} . \mathrm{HCl}\left(\mathrm{pH} 2\right.$ with $\mathrm{HNO}_{3}$ ), $20 \mathrm{ml}$, room temperature, shake for $16 \mathrm{~h}$ \\
\hline 3 & B3: organic matter and sulfide bound & $\begin{array}{l}30 \% \mathrm{H}_{2} \mathrm{O}_{2}, 5 \mathrm{ml} \text {, room temperature, } 1 \mathrm{~h} \text {, followed at } 85^{\circ} \mathrm{C}, 1 \mathrm{~h} \text {; occasionally shake; } \\
\text { add } 5 \mathrm{ml} 30 \% \mathrm{H}_{2} \mathrm{O}_{2}, 85^{\circ} \mathrm{C}, 1 \mathrm{~h} \text {; add } 1 \mathrm{M} \mathrm{NH}_{4} \mathrm{OAc}\left(\mathrm{pH} 2 \text { with } \mathrm{HNO}_{3}\right) 25 \mathrm{ml} \text {, } \\
\text { room temperature, shake } 16 \mathrm{~h}\end{array}$ \\
\hline Total $^{\mathrm{b}}$ & & $\mathrm{HNO}_{3}+\mathrm{HF}+\mathrm{HClO}_{4}, 3 \mathrm{ml}$, under high pressure, $170^{\circ} \mathrm{C}$ \\
\hline
\end{tabular}

a In steps $1-3,0.500 \mathrm{~g}$ of soil sample was used.

b Determination of the total content of individual REEs was performed independently by attacking $0.100 \mathrm{~g}$ soil (dry weight).

residues were then subject to further extractions in the next step. The fractionation scheme resulted in three chemically distinct fractions, namely, exchangeable and carbonate bound (B1), $\mathrm{Fe}-\mathrm{Mn}$ oxide bound (B2) and organics and sulfides (B3), as shown in Table 2.

\subsection{Inductively coupled plasma-mass spectrometry (ICP-MS) analysis}

The REE concentrations in soil and plant were determined by ICP-MS (VG PlasmaQuard III) after decomposition of samples with a mixture of $\mathrm{HNO}_{3} / \mathrm{HClO}_{4} / \mathrm{HF}$ (1:1:1) (Zhang and Shan, 1997). The extractable REEs in extractants were determined after diluting twice for the $\mathrm{B} 1$ fraction, and five times each for the B2 and B3 fractions. The ICP-MS operating conditions were optimized using a solution of ${ }^{115} \mathrm{In}$ at $20 \mathrm{ng} / \mathrm{ml}$ in $2 \%$ $\mathrm{HNO}_{3}$. An internal standard of ${ }^{115} \mathrm{In}$ at $20 \mathrm{ng} / \mathrm{ml}$ was used to compensate for matrix suppression and signal drift during analysis. All reagents used were of analytical reagent grade or better. Statistical analyses were carried out on the Software of Statistical Package for Social Science (SPSS).

The precision and accuracy of the elemental analysis were established by the determination of REEs in the certified reference materials (GSS-1, GSS-8 of soils and GBW 07605 of tea leaf from the National Research Center for Certified Reference Materials, Beijing, China). Seven replicates were made for each sample. The results are summarized in Table 3. Good agreements were achieved between the data obtained by the present method and the certified values for both the soils and tea leaf samples. The high precision of the analysis is also evidenced by the data listed in the table.

\section{Results and discussion}

\subsection{Properties of soils}

The ranges and means of the measured concentrations of each REE in the investigated soils are listed in Table 4 , together with the reported values of REEs in 77
Japanese soil samples (Yoshida et al., 1998). A comparison of the two groups of soils shows that the mean values of REEs in Chinese soils were higher than that in Japanese soils, especially for the elements $\mathrm{La}, \mathrm{Ce}, \mathrm{Pr}$, $\mathrm{Nd}$ and $\mathrm{Sm}$. The difference is probably due to the difference in the nature of the two soils. All the Chinese soils were collected from cultivated land, while the 77 Japanese soils were from rural or wild areas including upland fields, paddies, forest, and open countries throughout Japan.

\subsection{Relationship between crop yields and REE fertilizer application}

The relationship between crop yield, represented by dry shoot weights, and the level of REE fertilizer applied was investigated. The result is shown in Fig. 1. In order to exclude the factor of nitrate contribution towards plant growth, the total nitrate concentration in these runs was maintained at constant level through the addition of extra ammonium nitrate. Fig. 1 shows that for most of the soils, the dry shoot weight increased as the REE fertilizer applied increased from 0 to $2 \mathrm{mg}$ $\mathrm{REE} / \mathrm{kg}$ soil. The weight then stayed almost constant over the range of $2-40 \mathrm{mg}$ REE, followed by gradual reduction afterwards as the amounts of REE application increased further from 40 to $80 \mathrm{mg}$. The weight reduction at the final stage was probably due to the damage to plants by excessive concentrations of REE fertilizer.

For soil samples 2, 3, 4, 6 and 7, a positive correlation was obtained between the dry weight of shoot and the level of REE fertilizer application. The correlation was significant at 0.05 probability when the fertilizer concentration was lower than $40 \mathrm{mg} / \mathrm{kg}$. The correlation coefficients were $0.9367,0.9894,0.8788,0.9616$, and 0.8690 for soils $2,3,4,6$ and 7, respectively. Such correlation was not observed for soils 1 and 5 . For soil 1 , the shoot weight first increased dramatically at the low REE fertilizer concentration ranges, and then decreased steadily as the fertilizer concentration increased further. The dry shoot weight in soil 5 was nearly constant over the REE fertilizer concentration range studied. It is 
Table 3

Determination of rare earth elements (REEs) in the certified reference materials by inductively coupled plasma-mass spectrometry

\begin{tabular}{|c|c|c|c|c|c|c|}
\hline \multirow[t]{2}{*}{ Element } & \multicolumn{2}{|c|}{ GSS-1 soil $(\mu \mathrm{g} / \mathrm{g})$} & \multicolumn{2}{|c|}{ GSS-8 soil $(\mu \mathrm{g} / \mathrm{g})$} & \multicolumn{2}{|c|}{ GBW07605 tea leaves $(\mu \mathrm{g} / \mathrm{g})$} \\
\hline & This method ${ }^{\mathrm{a}}$ & Certified & This method ${ }^{\mathrm{a}}$ & Certified & This method ${ }^{\mathrm{a}}$ & Certified \\
\hline $\mathrm{Y}$ & $24.4 \pm 0.53$ & $25 \pm 4$ & $13.3 \pm 0.69$ & $15 \pm 2$ & $0.40 \pm 0.01$ & $0.36 \pm 0.03$ \\
\hline $\mathrm{La}$ & $35.0 \pm 2.71$ & $34 \pm 4$ & $21.1 \pm 0.82$ & $21 \pm 2$ & $0.62 \pm 0.07$ & $0.60 \pm 0.06$ \\
\hline $\mathrm{Ce}$ & $68.5 \pm 1.95$ & $70 \pm 5$ & $38.4 \pm 1.11$ & $39 \pm 6$ & $1.05 \pm 0.08$ & $1.0 \pm 0.1$ \\
\hline $\operatorname{Pr}$ & $7.41 \pm 0.22$ & $7.5 \pm 0.5$ & $4.52 \pm 0.20$ & $4.8 \pm 0.4$ & $0.10 \pm 0.02$ & $(0.12)$ \\
\hline $\mathrm{Nd}$ & $25.4 \pm 0.75$ & $28 \pm 3$ & $17.5 \pm 0.52$ & $18.4 \pm 2.4$ & $0.50 \pm 0.06$ & $(0.44)$ \\
\hline $\mathrm{Sm}$ & $5.16 \pm 0.29$ & $5.2 \pm 0.4$ & $3.10 \pm 0.09$ & $3.3 \pm 0.3$ & $0.09 \pm 0.01$ & $0.085 \pm 0.017$ \\
\hline $\mathrm{Eu}$ & $1.00 \pm 0.10$ & $1.0 \pm 0.1$ & $0.73 \pm 0.04$ & $0.72 \pm 0.06$ & $0.02 \pm 0.001$ & $0.018 \pm 0.002$ \\
\hline Gd & $4.76 \pm 0.24$ & $4.6 \pm 0.3$ & $3.12 \pm 0.12$ & $2.9 \pm 0.4$ & $0.10 \pm 0.003$ & $(0.093)$ \\
\hline $\mathrm{Tb}$ & $0.71 \pm 0.05$ & $0.75 \pm 0.09$ & $0.45 \pm 0.02$ & $0.49 \pm 0.09$ & $0.012 \pm 0.003$ & $(0.011)$ \\
\hline Dy & $4.29 \pm 0.13$ & $4.6 \pm 0.3$ & $2.37 \pm 0.19$ & $2.6 \pm 0.2$ & $0.076 \pm 0.002$ & $(0.074)$ \\
\hline Ho & $0.83 \pm 0.06$ & $0.87 \pm 0.09$ & $0.50 \pm 0.01$ & $0.53 \pm 0.07$ & $0.021 \pm 0.003$ & $(0.019)$ \\
\hline $\mathrm{Er}$ & $2.57 \pm 0.28$ & $2.6 \pm 0.2$ & $1.40 \pm 0.07$ & $1.5 \pm 0.3$ & $0.056 \pm 0.001$ & - \\
\hline $\mathrm{Tm}$ & $0.42 \pm 0.04$ & $0.42 \pm 0.07$ & $0.27 \pm 0.01$ & $0.28 \pm 0.06$ & $0.018 \pm 0.002$ & - \\
\hline $\mathrm{Yb}$ & $2.57 \pm 0.28$ & $2.66 \pm 0.33$ & $1.53 \pm 0.05$ & $1.68 \pm 0.22$ & $0.048 \pm 0.002$ & $(0.044)$ \\
\hline $\mathrm{Lu}$ & $0.36 \pm 0.02$ & $0.41 \pm 0.06$ & $0.23 \pm 0.02$ & $0.29 \pm 0.33$ & - & - \\
\hline
\end{tabular}

a Mean and standard deviation from seven determinations.

Table 4

Total content of each rare earth elements (REEs) in Chinese soils and Japanese soils

\begin{tabular}{|c|c|c|c|c|}
\hline \multirow[t]{2}{*}{ Element } & \multicolumn{2}{|c|}{ Concentration in seven Chinese soils $(\mu \mathrm{g} / \mathrm{g})$} & \multicolumn{2}{|c|}{ Concentration in 77 Japanese surface soils $\mathrm{s}^{\mathrm{a}}(\mu \mathrm{g} / \mathrm{g})$} \\
\hline & Range & Mean & Range & Mean \\
\hline $\mathrm{Y}$ & $13.9-24.7$ & 19.7 & - & - \\
\hline $\mathrm{La}$ & $21.8-39.8$ & 33.1 & $1.20-51.1$ & 18.2 \\
\hline $\mathrm{Ce}$ & $47.1-93.6$ & 72.8 & $2.46-116$ & 39.8 \\
\hline $\operatorname{Pr}$ & $5.17-8.53$ & 7.61 & $0.28-11.7$ & 4.53 \\
\hline $\mathrm{Nd}$ & $19.0-29.9$ & 26.2 & $1.08-43.5$ & 17.6 \\
\hline $\mathrm{Sm}$ & $4.06-5.69$ & 4.90 & $0.21-8.73$ & 3.67 \\
\hline $\mathrm{Eu}$ & $0.87-1.28$ & 1.08 & $0.05-2.57$ & 0.96 \\
\hline $\mathrm{Gd}$ & $3.75-5.37$ & 4.74 & $0.23-8.71$ & 3.71 \\
\hline $\mathrm{Tb}$ & $0.57-0.79$ & 0.70 & $0.03-1.40$ & 0.56 \\
\hline Dy & $3.26-4.78$ & 4.27 & $0.19-8.21$ & 3.29 \\
\hline Ho & $0.64-0.90$ & 0.82 & $0.04-1.80$ & 0.68 \\
\hline $\mathrm{Er}$ & $1.59-2.58$ & 2.28 & $0.13-5.10$ & 1.99 \\
\hline $\mathrm{Tm}$ & $0.24-0.42$ & 0.35 & $0.02-0.77$ & 0.29 \\
\hline $\mathrm{Yb}$ & $2.09-2.39$ & 2.20 & $0.12-4.99$ & 2.00 \\
\hline $\mathrm{Lu}$ & $0.28-0.37$ & 0.36 & $0.02-0.78$ & 0.29 \\
\hline
\end{tabular}

a Yoshida et al. (1998).

evident that the nature of the soil plays an important role on the overall effects of REEs towards plant growth.

\subsection{Plant accumulation of REEs}

The means and ranges of the concentrations of $\mathrm{La}, \mathrm{Ce}$, $\mathrm{Pr}$ and $\mathrm{Nd}$ in shoot and root parts of the wheat samples after the application of different concentrations of REE fertilizers are listed separately in Table 5. The REE accumulations in both the root and shoot were found to increase significantly with increasing concentration of REE fertilizer application. The relationships between REE accumulation in both the root and shoot and the concentration of REE fertilizer applied were closely similar for all REE elements of $\mathrm{La}, \mathrm{Ce}, \mathrm{Pr}$ and $\mathrm{Nd}$. Thus, La is chosen as a representative case for illustration in later discussions.

Plots of La accumulation versus REE fertilizer concentration are shown in Figs. 2 (root) and 3 (shoot). Overall, the La accumulation in both the root and shoot increased at low fertilizer concentration levels from 0 to $10 \mathrm{mg} / \mathrm{kg}$ soil, and then stayed constant at higher concentrations. The two exceptions were soils 2 and 3, for which the accumulation of La increased steadily with increasing La fertilizer concentration over the entire range studied. Such increase in root was more pronounced than those in shoot. Generally, the La concentrations in roots were much higher than that in shoots. The average ratio of $\mathrm{La}$ in root to shoot was 


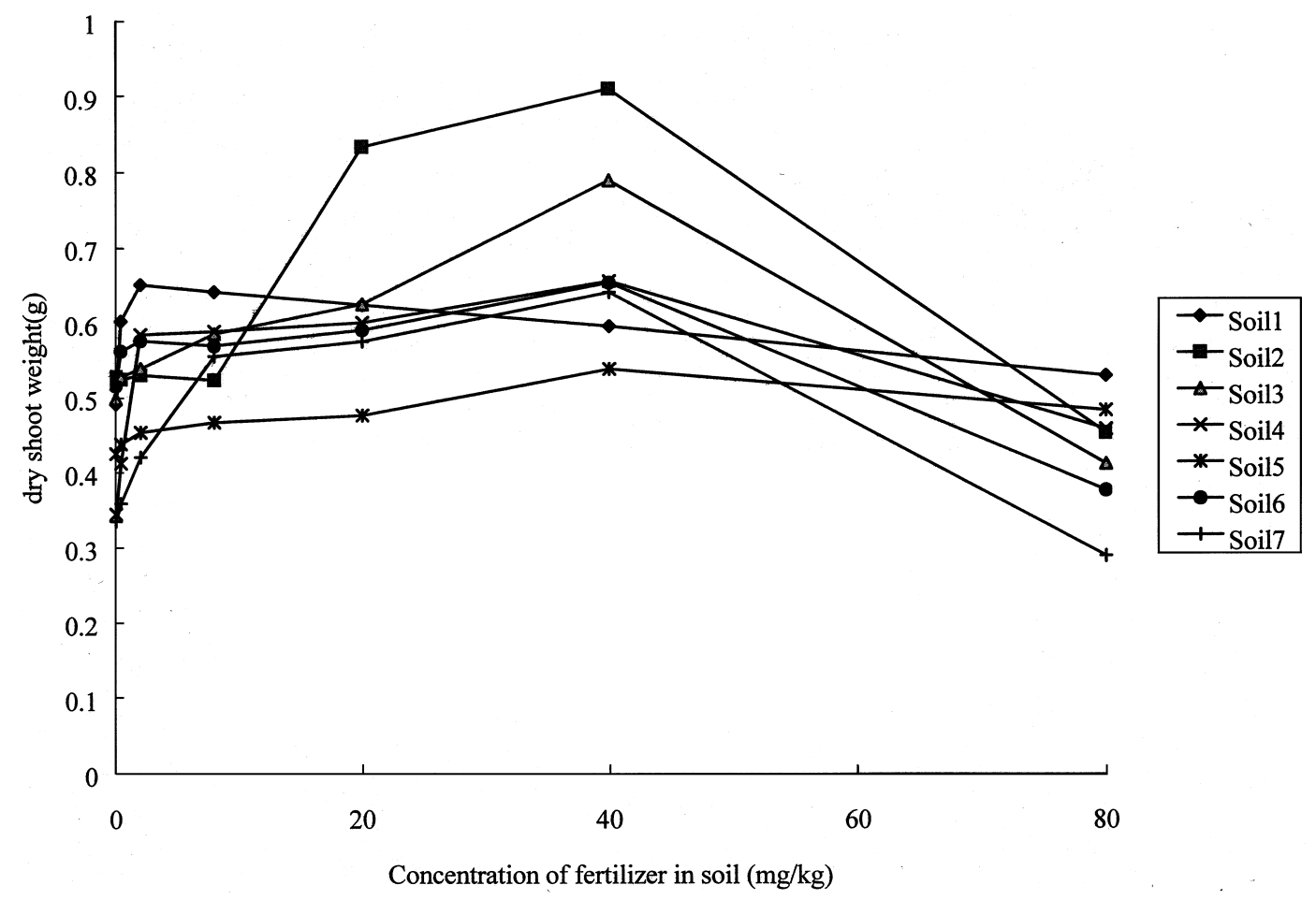

Fig. 1. Relationship between dry shoot weight and rare earth element (REE) fertilizer applied.

Table 5

Mean and range of rare earth elements (REEs) in the shoot and root for different concentration of REE fertilizer with seven Chinese soils

\begin{tabular}{|c|c|c|c|c|c|c|c|c|c|}
\hline & \multirow[t]{3}{*}{ Fertilizer added $(\mathrm{mg} / \mathrm{kg})$} & \multicolumn{8}{|c|}{ Concentration of REEs in shoot and root $(\mu \mathrm{g} / \mathrm{g})$} \\
\hline & & \multicolumn{2}{|l|}{$\mathrm{La}$} & \multicolumn{2}{|l|}{$\mathrm{Ce}$} & \multicolumn{2}{|l|}{$\operatorname{Pr}$} & \multicolumn{2}{|l|}{$\mathrm{Nd}$} \\
\hline & & Mean & Range & Mean & Range & Mean & Range & Mean & Range \\
\hline \multirow[t]{7}{*}{ Shoot } & 0 & 0.21 & $0.12-0.43$ & 0.40 & $0.19-0.68$ & 0.04 & $0.028-0.057$ & 0.13 & $0.08-0.15$ \\
\hline & 0.4 & 0.37 & $0.24-0.62$ & 0.61 & $0.37-0.98$ & 0.06 & $0.040-0.087$ & 0.20 & $0.13-0.26$ \\
\hline & 2.0 & 0.57 & $0.26-0.97$ & 0.92 & $0.41-1.8$ & 0.097 & $0.048-0.19$ & 0.29 & $0.15-0.54$ \\
\hline & 8.0 & 0.79 & $0.33-1.3$ & 1.3 & $0.59-2.3$ & 0.14 & $0.066-0.25$ & 0.44 & $0.27-0.69$ \\
\hline & 20 & 2.1 & $0.46-4.1$ & 3.8 & $0.79-4.7$ & 0.38 & $0.087-0.74$ & 1.2 & $0.30-2.5$ \\
\hline & 40 & 2.2 & $0.56-4.2$ & 4.2 & $1.0-7.5$ & 0.42 & $0.11-0.76$ & 1.3 & $0.34-2.5$ \\
\hline & 80 & 2.6 & $0.91-4.28$ & 5.1 & $1.6-7.2$ & 0.51 & $0.17-0.73$ & 1.5 & $0.51-2.5$ \\
\hline \multirow[t]{7}{*}{ Root } & 0 & 3.3 & $1.1-10.0$ & 6.7 & $1.6-24.4$ & 0.63 & $0.18-1.8$ & 2.8 & $1.0-5.9$ \\
\hline & 0.4 & 3.5 & $1.1-10.8$ & 7.3 & $1.8-26.4$ & 0.66 & $0.20-1.9$ & 3.2 & $1.2-7.1$ \\
\hline & 2.0 & 5.0 & $1.2-12.6$ & 8.9 & $2.1-29.0$ & 0.84 & $0.84-2.1$ & 3.2 & $1.1-6.9$ \\
\hline & 8.0 & 7.4 & $1.5-19.2$ & 13.4 & $2.6-42.9$ & 1.4 & $0.44-3.3$ & 4.6 & $1.5-11.1$ \\
\hline & 20 & 9.8 & $2.8-18.0$ & 19.4 & $5.2-39.0$ & 1.8 & $0.58-3.2$ & 5.7 & $1.8-10.0$ \\
\hline & 40 & 12.7 & $5.7-19.7$ & 24.5 & $10.4-38.4$ & 2.3 & $1.1-3.5$ & 7.3 & $3.4-10.9$ \\
\hline & 80 & 17.7 & $3.8-35.5$ & 32.5 & $6.4-74.4$ & 3.1 & $0.76-6.4$ & 9.5 & $2.3-18.9$ \\
\hline
\end{tabular}

about 10 , indicating the much greater La accumulation potential of roots. This observation is consistent with the general behavior of plants in their response towards environmental stress. Thus, the translocation of heavy metals to the aboveground portions of the plants is minimized in order to minimize the toxic effects caused by metals in soil (Foy, 1983).

The importance of $\mathrm{pH}$ in controlling the bioactivity and bioavailability of metals in soils is widely recog- nized (Shuman, 1975; Harter, 1983). In this study, it was observed that the soil $\mathrm{pH}$ had an inverse relationship to the REE concentration in roots. A negative correlation was obtained between the total root contents of $\mathrm{La}, \mathrm{Ce}$, $\mathrm{Pr}$ and $\mathrm{Nd}$ and the soil $\mathrm{pH}$. Such correlation was especially significant for the run with $20 \mathrm{mg} / \mathrm{kg}$ fertilizer application (Table 6). The results are consistent with the general expectation of greater bioavailability of trace metals at lower soil $\mathrm{pH}$, since increasing amounts of 


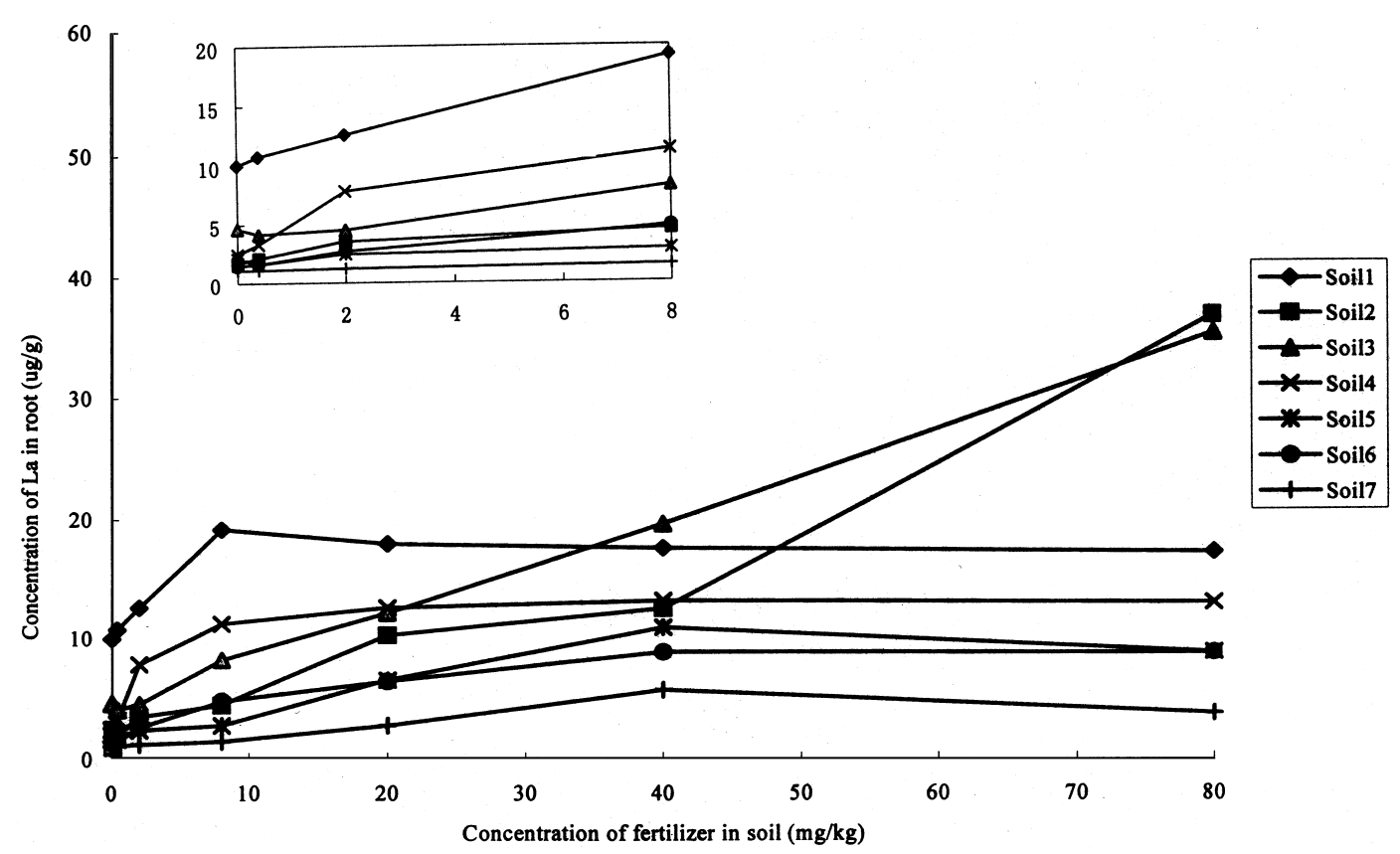

Fig. 2. Relationship between the concentration of $\mathrm{La}$ in root and the concentration of rare earth element (REE) fertilizer applied.

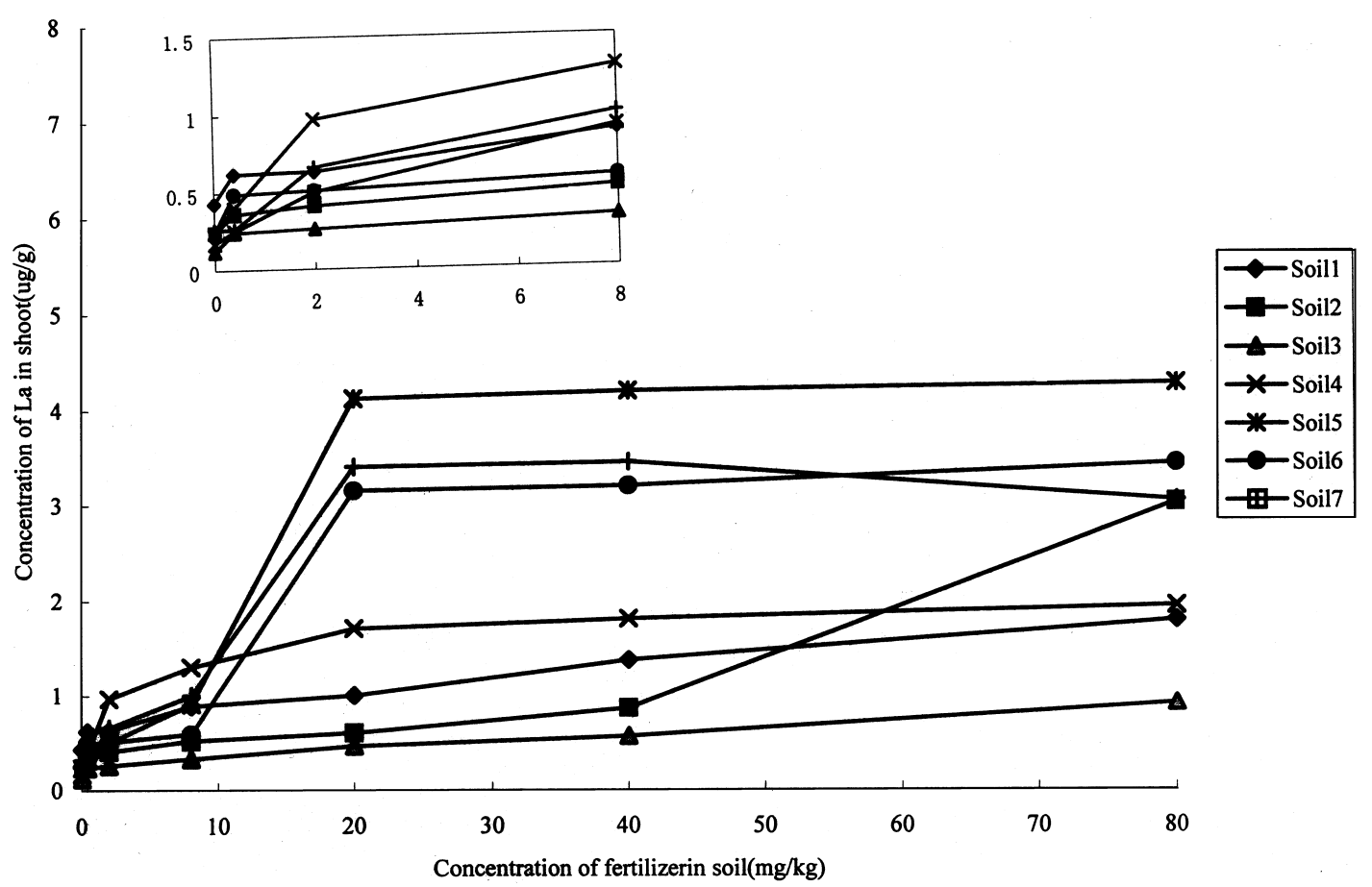

Fig. 3. Relationship between the concentration of La in shoot and the concentration of rare earth element (REE) fertilizer applied.

metals would be precipitated as insoluble hydroxides, carbonates and as organic complexes as the soil $\mathrm{pH}$ increases. In addition, the adsorption of metals onto the surface of clay minerals, or their partition into the organic matter also increase with increasing soil $\mathrm{pH}$.

As we can see from Figs. 2 and 3, large differences existed between root and shoot accumulation of REEs. Fig. 2 shows that the root accumulation of $\mathrm{La}$ in soils with lower $\mathrm{pH}$ was significantly higher, either in accu- mulation rate (soils 2 and 3 ) or in total amount (soil 1), than those with higher $\mathrm{pH}$. Contrary to these, Fig. 3. shows that the shoot accumulation of $\mathrm{La}$ in soils 1,2 and 3 were lower than those of other soils. Correlation analysis shows that there was a significant negative correlation between La content in root and soil $\mathrm{pH}$. Such negative correlation was not observed in the case of shoot samples. In fact, for the $20 \mathrm{mg}$ fertilizer $/ \mathrm{kg}$ soil run, a positive, rather than negative, correlation 
Table 6

Correlation coefficient for La in plant and $\mathrm{pH}$ of soil $(n=7)$

\begin{tabular}{|c|c|c|c|c|c|c|c|}
\hline & \multicolumn{7}{|c|}{ Concentration of fertilizer added $(\mathrm{mg} / \mathrm{kg})$} \\
\hline & 0 & 0.4 & 2.0 & 8.0 & 20 & 40 & 80 \\
\hline Root & $-0.7564 * *$ & $-0.7749 * *$ & $-0.7365^{*}$ & $-0.7193 *$ & $-0.8442 * *$ & $-0.6834^{*}$ & -0.5787 \\
\hline Shoot & 0.5502 & 0.5954 & 0.1716 & 0.2230 & $0.7018^{*}$ & $0.6549 *$ & 0.3544 \\
\hline
\end{tabular}

*Significant at 0.10 probability level.

**Significant at 0.050 probability level.

between shoot La and soil $\mathrm{pH}$ was suggested by the data (Table 6).

The phytoaccumulation characteristics of REEs in plants has been the subject of several recent reports. Some researches (Xie et al., 1999) claimed that REE deposition occurs only at extracellular or apoplastic locations. Similarly, other researchers (Kelley et al., 1999) have shown that when water hyacinth root was incubated with Eu, accumulation of Eu occurred primarily by adsorption onto the surface of the root. The difference in accumulation behavior between root and shoot observed in this study would then simply be a reflection of the different mechanisms involved in plant uptake and bioaccumulation. The $\mathrm{pH}$ dependence of the accumulation behavior can also be explained by the study of Chen et al. (1995). They rationalized that the soil $\mathrm{pH}$ could change the structures of the cell wall and plasmolemma of the plant, and also the osmotic pressure of the plasma inside the plant. In acidic soils such as soils 1, 2 and 3, the REE ions could hardly enter the cell along with the fluid. Thus, the uptake of REEs by the above-soil part of the plant (shoot) was inhibited, resulting in lower REE accumulation.

\subsection{Speciation of REEs by sequential extractions}

A sequential extraction scheme was used to speciate the chemical types of REEs in soils. The extraction procedure was originally developed for the determination of extractable trace metals in sediments (Quevauviller et al., 1993). It has been successfully applied to the studies of soils for both the trace metals (McGrath 1996) and REEs (Li et al., 1998). The extraction procedure resulted in three chemically distinct fractions: (1) exchangeable and carbonate-bound REEs (B1); (2) $\mathrm{Fe}-\mathrm{Mn}$ oxide-bound REEs (B2); and (3) organic- and sulfide-bound REEs (B3), as given earlier in Table 2 . Again, La will be used as a representative REE for the discussions given below since the behavior of the other REE elements is closely similar.

Figs. 4-6 show the concentrations of La in each of the three extracted fractions in soils with different concentrations of REE fertilizers applied. The extraction percentages of $\mathrm{La}$ in fractions $\mathrm{B} 1, \mathrm{~B} 2$ and $\mathrm{B} 3$ ranged from 0.22 to 4.6 (mean value is $1.2 \%$ ), 1.9 to 11.0 (mean value is $5.0 \%$ ) and 4.8 to $28.4 \%$ (mean value is $12.2 \%$ ) of the total La content in fertilized and unfertilized soils, respectively. It appears that the chemical forms of $\mathrm{La}$ introduced by the REE fertilizers were closely similar to those of the endogenous $\mathrm{La}$ in the soils. Taking soil 1 as an example, it had higher endogenous La concentrations in B1 and B2 but lower concentration in B3 fraction compared with other soils. Similarly, the percentages of $\mathrm{La}$ after the application of fertilizers were also higher in the $\mathrm{B} 1$ and $\mathrm{B} 2$ fractions, and lower in the B3 fraction compared with other soils.

The proportion of $\mathrm{La}$ in the fertilizer entering the B1 fraction was very small compared with those in the other two fractions. The exception was soil 1 for which the $\% \mathrm{La}$ in $\mathrm{B} 1$ was significantly higher (10.3-16.0 vs. $0.9-5.1 \%$ for the rests). The high fractional yield of B1 in soil 1 could be the result of low $\mathrm{pH}$ of the soil. The association of metals with different geochemical phases are known to depend on soil $\mathrm{pH}$. Low soil $\mathrm{pH}$ favors the conversion of metals from precipitable forms into soluble forms (Harter, 1983), which would be fractionated into the $\mathrm{B} 1$ fraction. A single correlation analysis was also performed to examine the relationship between REE distribution in soil fractions and soil $\mathrm{pH}$. The results shown in Table 7 indicate that the La content in B1 fraction is negatively correlated with the soil $\mathrm{pH}$, consistent with the general observation given earlier.

The percentages of $\mathrm{La}$ in the fertilizer entering the B2 fraction ranged from 6.0 to $27.4 \%$. Soils 1 and 2 represent samples with the highest contents of $\mathrm{La}$ in the B2 fraction than the other soils. These two soils were collected on the basalt weathering crust and had low soil $\mathrm{pH}$. Under the hot and humid conditions of the subtropical zone where these soils were collected, the primary minerals were broken down completely but the insoluble $\mathrm{Fe}-\mathrm{Mn}$ oxides were enriched. Significant negative correlations were obtained between La contents in the $\mathrm{B} 2$ fraction and the soil $\mathrm{pH}$, similar to those observed in B1 fraction given earlier (Table 7). One can therefore conclude that the soil $\mathrm{pH}$ also plays an important role in influencing $\mathrm{La}$ bindings to $\mathrm{Fe}-\mathrm{Mn}$ oxides.

The percentages of La in the fertilizer entering the B3 fraction ranged from 9.0 to $51.0 \%$, which were the highest among the three fractions. The lowest fractional yield was found in soil 1, while the highest in soil 5 . The 


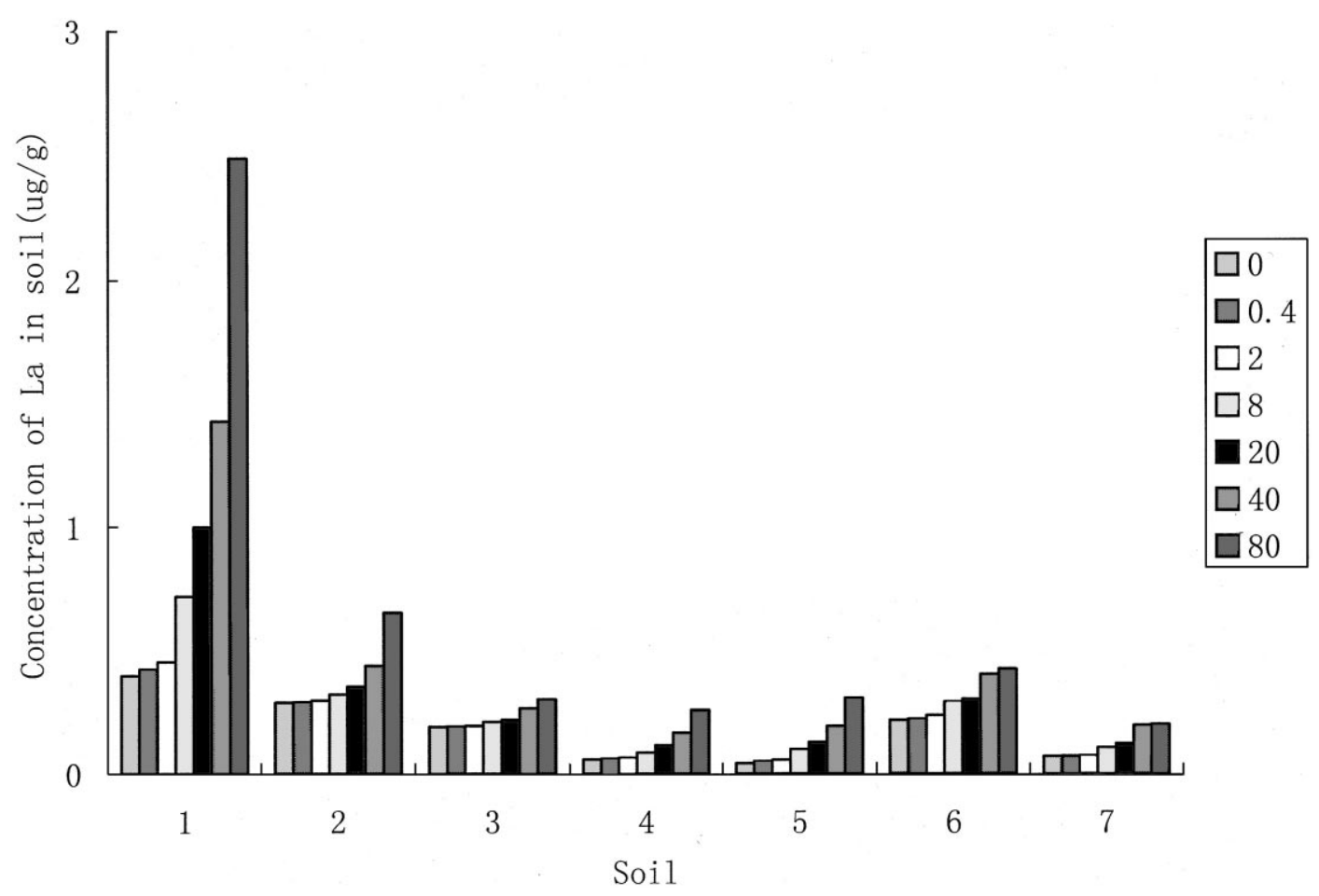

Fig. 4. Content of La in B1 fraction for different soil under the various condition of concentration of fertilizer applied (from 0 to $80 \mathrm{mg} / \mathrm{kg}$ soil).

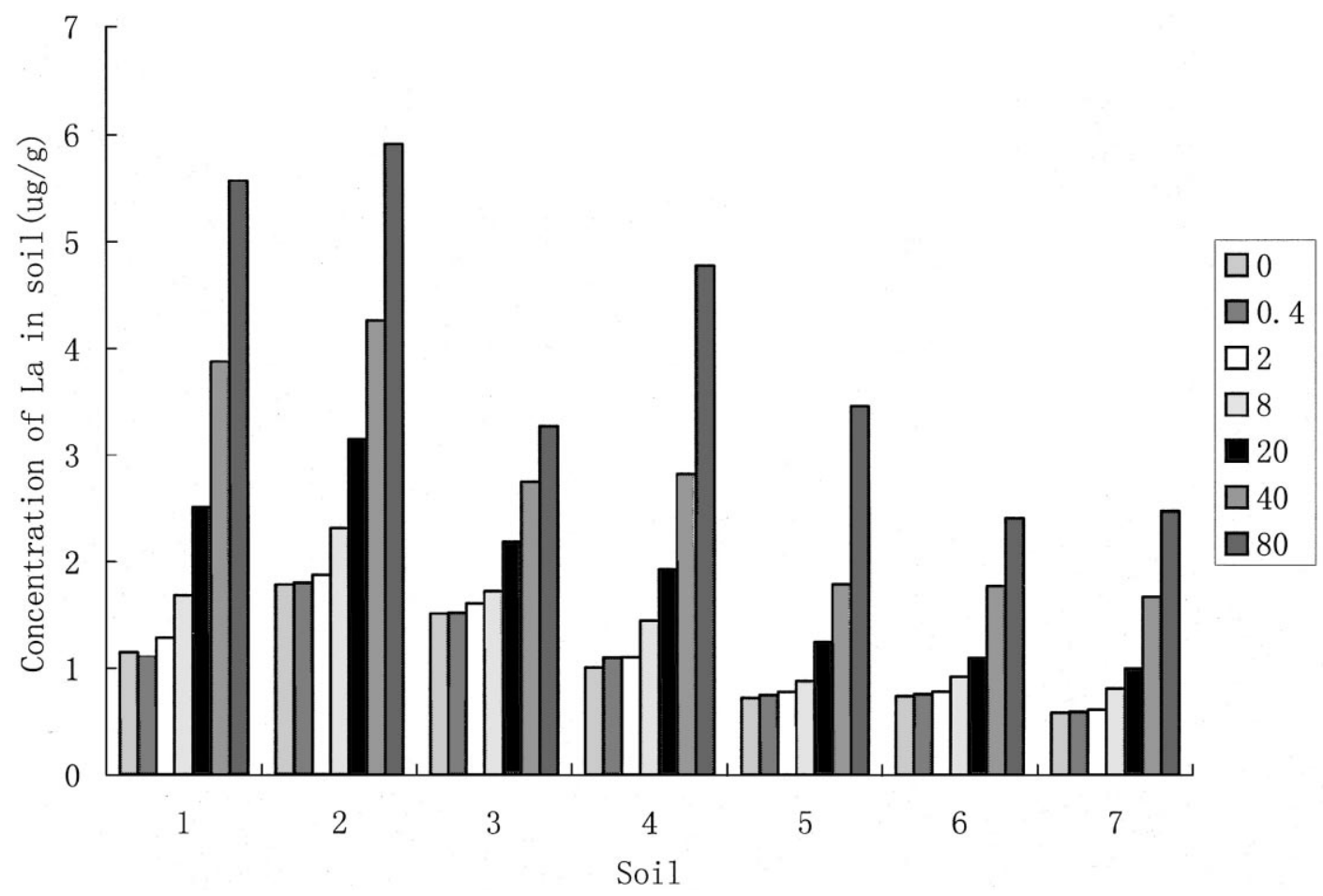

Fig 5. Content of La in B2 fraction for different soil under the various condition of concentration of fertilizer applied (from 0 to $80 \mathrm{mg} / \mathrm{kg}$ soil).

high La content of $\mathrm{B} 3$ in soil 5 was likely related to the high organic content of the soil, which was collected from northeast China. Situated in a humid frigidtemperature zone, the soil contained higher proportion of organic matter, especially high molecular weight organic compounds including humic acids. It has been reported that the amount of humic acid is about twice as much as that of fulvic acid in soils from this part of the country (Wang et al., 1996). The REEs in these soils are expected to bind strongly with the organics 


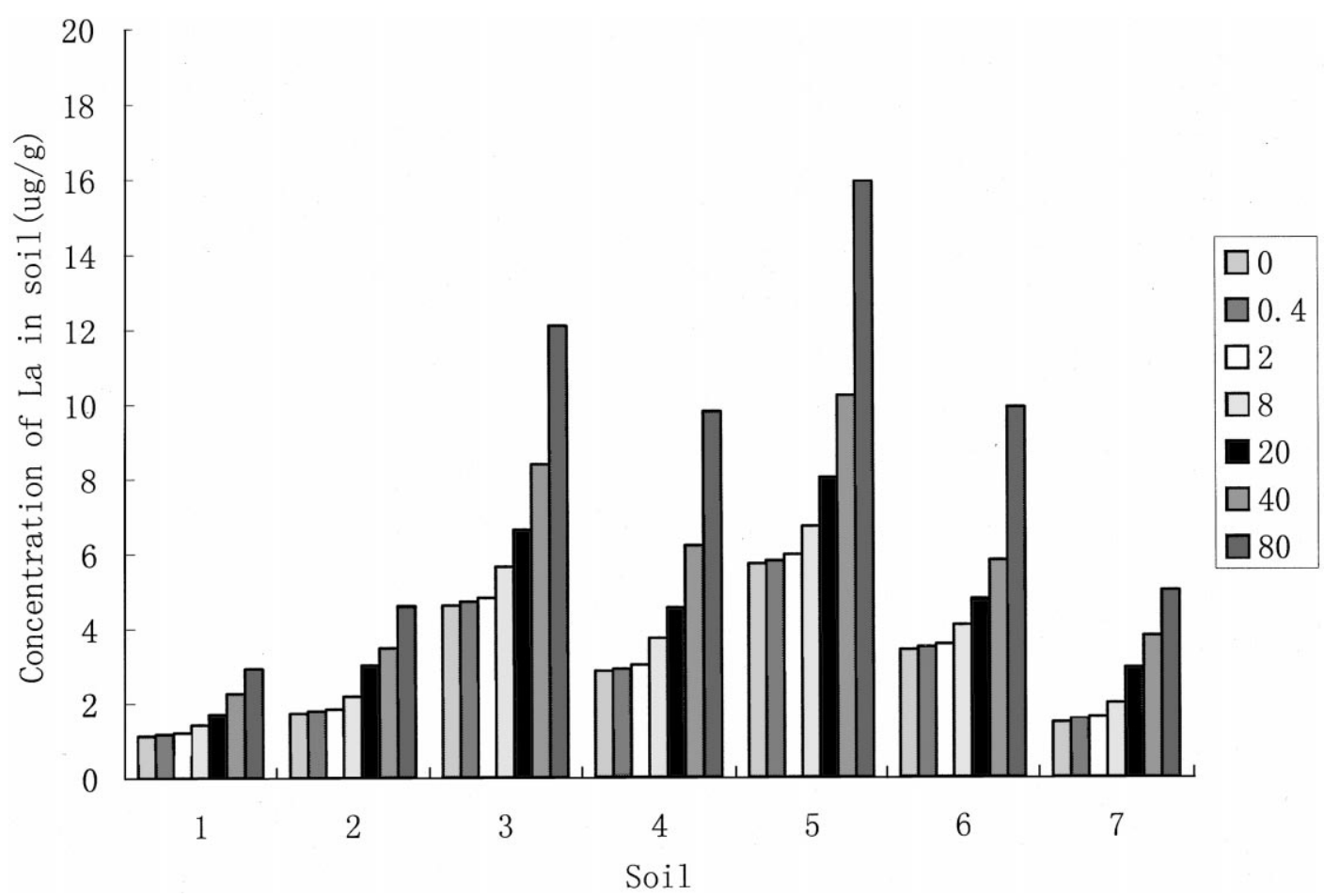

Fig. 6. Content of La in B3 fraction for different soil under the various condition of concentration of fertilizer applied (from 0 to $80 \mathrm{mg} / \mathrm{kg}$ soil).

Table 7

Correlation coefficient for $\mathrm{La}$ in soil fraction and $\mathrm{pH}$ of soil $(n=7)$

\begin{tabular}{|c|c|c|c|c|c|c|c|}
\hline \multirow[t]{2}{*}{ Fraction } & \multicolumn{7}{|c|}{ Concentration of fertilizer added $(\mathrm{mg} / \mathrm{kg})$} \\
\hline & 0 & 0.4 & 2.0 & 8.0 & 20 & 40 & 80 \\
\hline B1 & $-0.8208 * *$ & $-0.8927 * *$ & $-0.8107 * *$ & $-0.7488 *$ & $-0.7268^{*}$ & $-0.6892 *$ & $-0.7042^{*}$ \\
\hline B2 & $-0.7685^{* *}$ & $-0.7462 *$ & $-0.7888 * *$ & $-0.8551^{* *}$ & $-0.9165^{* *}$ & $-0.9482 * *$ & $-0.8916^{* *}$ \\
\hline B3 & 0.3583 & 0.3621 & 0.3630 & 0.3798 & 0.4266 & 0.4367 & 0.4570 \\
\hline Total & 0.0022 & 0.2057 & 0.1689 & 0.3207 & 0.2965 & 0.4012 & 0.4001 \\
\hline
\end{tabular}

*Significant at 0.10 probability level.

**Significant at 0.050 probability level.

through complexations, resulting in their enrichment in the $\mathrm{B} 3$ fraction.

In summary, the fractional yields of REEs in soils were in the order of B3 $>$ B2 $>$ B1. Only a small fraction of the REEs existed as water-soluble, exchangeable and carbonate-bound forms. The distribution of REEs in different fractions varied greatly with the soil types. The amounts of REEs in both B1 and B2 fractions showed significant negative correlation with the soil $\mathrm{pH}$; and soil $\mathrm{pH}$ was found to be the most important factor affecting the association of REEs with different geochemical phases.

\subsection{Relationship between plant uptake and speciations of REEs}

Single correlation analysis was performed to investigate the relationships between different chemical types of REEs and their plant uptake. The uptakes by root and shoot were treated separately in correlation analysis. For the root samples as shown in Table 8, significant correlation was observed between the root and the B1 fractional contents of La. The correlation coefficients for La ranged from 0.6159 to 0.7410 in runs with fertilizer application lower than $20.0 \mathrm{mg} / \mathrm{kg}$. No significant correlation was observed between the La contents in root and the total La contents in soils, or its fractional contents in B2 and B3 fractions. Thus, among all different fractions, B1 represents the one in which the REEs are the most bioavailable for plant uptake.

Variations in the REE contents in shoots were not easily predicated by measuring extractable REEs. La, $\mathrm{Ce}, \mathrm{Pr}$, and $\mathrm{Nd}$ extracted in any of the fractions did not show significant correlation with their corresponding uptakes by the shoot. The physiological processes of REE uptake in plant are very complex, as demonstrated 
Table 8

Correlation coefficients for La in root and soil fraction $(n=7)$

\begin{tabular}{lccccrr}
\hline Fraction & \multicolumn{6}{l}{ Concentration of fertilizer added $(\mathrm{mg} / \mathrm{kg})$} \\
\cline { 2 - 7 } & 0 & 0.4 & 2.0 & 8.0 & 20 & 40 \\
\hline B1 & $0.6913^{*}$ & $0.6703^{*}$ & 0.6159 & $0.7410^{*}$ & $0.7213^{*}$ & 0.4458 \\
B2 & 0.2595 & 0.2347 & 0.3088 & 0.4003 & $0.7212^{*}$ & 0.6014 \\
B3 & -0.2793 & -0.2937 & -0.3900 & -0.3429 & -0.2906 & 0.1195 \\
Total & 0.4086 & 0.2473 & 0.2095 & 0.392152 & 0.0315 \\
\hline
\end{tabular}

*Significant at 0.1 probability level.

by the recent work of Wyttenbach et al. (1998). The study showed that the uptake of REE is different for the same species but grown in different soils. Moreover, even for plants grown in the same soil, the uptake behavior of individual plants may still be different even though they all belong to the same species.

\section{Conclusion}

The present study demonstrated that most of the La, $\mathrm{Ce}, \mathrm{Pr}$ and $\mathrm{Nd}$ in soils after the application of REE fertilizer were found in the $\mathrm{B} 2$ ( $\mathrm{Fe}-\mathrm{Mn}$ oxide-associated) and B3 (organic- and sulfide-associated) fractions, with only a small portion of them found in the B1 (cation exchangeable or soluble) fraction. The bioaccumulation potential of REEs could be predicted by the fractional yield of REEs in the B1 fraction. Significant accumulation of REEs was found in both the root and shoot parts of wheat. Further research is in progress to speciate the specific chemical forms of REEs, and to gain better understanding on the physiological processes of their uptake by plants. These studies would hopefully provide more quantitative information for the assessment of the health and environmental risks associated with the large-scale application of REE fertilizers.

\section{Acknowledgements}

Financial support from Chinese Academy of Sciences and the National Natural Science Foundation of China and the Research Center for Eco-Environmental Sciences (KIP-9901) are gratefully acknowledged. The authors thank Professor Lee Sen-Chun Frank for the improvement of English

\section{References}

Chen, Z., Wang, X., Tian, L., 1995. Distribution of extractable rare earth elements in soil. Journal of the Chinese Rare Earth Society 13, 74-77.
Ding, G.S., Ma, H.C., 1984. Effects of rare earths on organisms. Chinese Journal of Environmental Sciences 5 (2), 70-75.

Foy, C.D., 1983. The physiology of plant adaptation to mineral stress. Iowa State Journal of Researches 57, 355-391.

Guo, B., 1985. Present and future situation of rare earth in China's agronomy. In: Xu, G., Xiao, J. (Eds.), Proceeding of the International Conference on Rare Earth Development and Application, Vol. 2. Academic Press, Beijing, China, pp. 1522-1527.

Harter, R.D., 1983. Effect of soil pH on adsorption of lead, copper, zinc, and nickel. Soil Science Society of American Journal 47, 47-51.

Ichihashi, H., Morita, H., Tatsukawa, R., 1992. Rare earth elements (REEs) in naturally grown plants in relation to their variation in soils. Environmental Pollution 76, 157-162.

Kelley, C., Mielke, R.E., Dimaquibo, D., Curtis, A.J., Dewitt, J.G., 1999. Adsorption of Eu (III) onto roots of water hyacinth. Environmental Science and Technology 33, 1439-1443.

Li, F., Shan, X., Zhang, T., Zhang, S., 1998. Evaluation of plant availability of rare earth elements in soils by chemical fractionation and multiple regression analysis. Environmental Pollution 102, 269-277.

Liu, C., Masuda, A., Okada, A., Yabuki, S., Zhang, J., Fan, A., 1993. A geochemical study of loess and desert sand in northern China: implications for continental crust weathering and composition. Chemical Geology 106, 359-374.

McGrath, D., 1996. Application of single and sequential extraction procedures to polluted and unpolluted soils. Science of the Total Environment 178, 37-44.

Nelson, D.W., Sommers, L.E., 1982. Total carbon, organic carbon, and organic matter. In: Page, S.L., Miller, R.H., Keeney, D.R. (Eds.), Methods of Soil Analysis. Part 2. American Society of Agronomy, Madison, WI, pp. 539-579.

Ning, J., 1985. The results of applying rare earth element to rice and other crops. In: Xu, G., Xiao, J. (Eds.), Proceeding of International Conference on Rare Earth Development and Application, Vol. 2. Academic Press, Beijing, China, pp. 1518-1524.

Quevauviller, Ph., Rauret, G., Griepink, B., 1993. Single and sequential extraction in sediments and soils. International Journal of Environmental Analytical Chemistry 51, 231-235.

Rhoades, J.D., 1982. Cation-exchange capacity. In: Page, A.L., Miller, R.H., Deeney, D.R. (Eds.), Methods of Soil Analysis. Part 2. America Society of Agronomy, Madison, WI, pp. 149-158.

Sabbioni, E., Pietra, R., Gaglione, P., Vocaturo, G., Colombo, F., Zanoni, M., Roddi, F., 1982. Long-term occupational risk of rare earth pneumoconiosis. Science of the Total Environment 26, 19-32.

Sax, N.I. (Ed.), 1984. Dangerous Properties of Industrial Materials. Van Nostrand Reinhold, New York, pp. 2358-2368.

Scott, A.W., 1990. The aqueous geochemistry of the rare earth elements and yttrium. Chemical Geology 82, 159-186.

Shuman, L.M., 1975. The effect of soil properties on $\mathrm{Zn}$ adsorption by soils. Soil Science Society of American Journal 39, 454-458. 
Tu, Q., Wang, X., Tian, L., Dai, L., 1994. Bioaccumulation of the rare earth elements lanthanum, gadolinium and yttrium in carp. Environmental Pollution 85, 345-350.

Volokh, A.A., Gorbunov, A.V., Gundorina, S.F., Revich, B.A., Frontasyeva, M.V., Chen, S.P., 1990. Phosphorus fertilizer production as a source of rare-earth elements pollution of the environment. Science of the Total Environment 95, 141-148.

Wang, Y., Sun, J., Chen, H., Guo, F., Wang, L., Zhang, S., 1996. Study of speciation of rare earth elements in soil. Journal of Nuclear Radiochemistry 18, 146-151.

Wronkiewicz, D.J., Condie, K.C., 1990. Geochemistry and mineralogy of sediments from the ventersdrop and transvaal supergroups, South Africa: cratonic evolution during the earth proterozoic. Geochimica et Cosmochimica Acta 54, 343-354.

Wu, Z., Guo, B., 1995. Application of REEs in agriculture and medicines. In: Ni, G. (Ed.), Bioinorganic Chemistry of Rare Earth Elements. Academic Press, Beijing, China, pp. 13-55.
Wyttenbach, A., Furrer, C., Schleppi, P., Tobler, L., 1998. Rare earth elements in soil and in soil-grown plants. Plant and Soil 199, 267-273.

Xie, X., Xu, L., Cai, J., Zha, L., Huang, B., 1999. Distribution of Lanthanum in soybean seedling roots. Chinese Rare Earths 20, $61-63$.

Yoshida, S., Muramatsu, Y., Tagami, K., Uchida, S., 1998. Concentrations of Lanthanide elements, Th, and $U$ in 77 Japanese surface soils. Environment International 24, 275-286.

Yu, Z., Chen, M. (Eds.), 1995. Rare Earth Elements and Their Applications. Metallurgical Industry Press, Beijing, pp. 286-294.

Zhang, S., Shan, X., 1997. The determination of rare earth elements in soil by inductively coupled plasma mass spectrometry. Atomic Spectroscopy 18, 140-144.

Zhu, W., Kennedy, M., de Leer, E.W.B., Zhou, H., Alaerts, G.J.F.R., 1997. Distribution and modeling of rare earth elements in Chinese river sediments. Science of the Total Environment 204, 233-243. 